\title{
COVID-19 Pozitif Hastaya Hemşirelik Bakımı Veren Bir Hemşirenin Deneyimleri: Olgu Sunumu
}

\section{The Experiences of a Nurse Giving the Nursing Care to COVID-19 Positive Patients: A Case Report}

\author{
${ }^{1,2}$ Canan BİRIMOĞLU OKUYAN, ${ }^{3}$ Elifnur GÜNEŞ, ${ }^{4}$ Esra YEŞILYURT \\ ${ }^{1}$ Sakarya Uygulamalı Bilimler Üniversitesi, Sağlık Bilimleri Fakültesi Sakarya, Türkiye. \\ ${ }^{2}$ Western Ontario Üniversitesi, Ontario, Kanada. \\ ${ }^{3}$ Manchester Metropolitan Universitesi, Manchester, İngiltere. \\ ${ }^{4}$ Gülhane Eğitim ve Araştırma Hastanesi, Ankara, Türkiye. \\ Canan Birimoğlu Okuyan: https://orcid.org/0000-0002-7339-6072 \\ Elifnur Güneş : https://orcid.org/0000-0003-3202-5619 \\ Esra Yeşilyurt: https://orcid.org/0000-0001-6110-6675
}

\section{ÖZ}

Pandemiler, sağllk sistemi üzerinde büyük etkisi olan ve ciddi ölümlere neden olan önemli bir halk sağlığı sorunudur. Sağlık çalışanları içerisinde en büyük grubu oluşturan ve COVID-19 pandemisi sürecinde zor görevler üstlenen hemşireler, doğrudan hasta bakımı ve iyileşmesinde ve salgının kontrolünde etkin rol oynayan hayati insan kaynaklarıdır. Katlanarak büyüyen salgın süreci ancak hemşirelerin refahını artırılarak yönetilebilir ve virüsün sağlık sektörü içinde yayılma riski bu şekilde minimumda tutulabilir. Hemşireler sağlık, bakım ve destek hizmetlerinin koordinasyonunda kritik bir rol oynamaktadır ve salgınlara karş1 mücadelede ön plandadırlar. Bu nedenle hemşireler hastane tarafindan sağlık güvenliği sağlanarak iyi desteklenmelidir. $\mathrm{Bu}$ olgu sunumunda salgın sürecinde COVID-19 pozitif hastalara bakım veren bir hemşirenin karşılaştığı sorunlar ile ilgili duygu ve düşünceleri açıklanmaktadır.

Anahtar Kelimeler: Klinik deneyim, salgın, olgu sunu$\mathrm{mu}$

\section{ABSTRACT}

Pandemics are significant health problems that have a great impact on the health care system and causes serious deaths. Nurses are the largest group among healthcare professionals, and they perform difficult role in the control of the disease such as direct patient care and recovery during the COVID-19 pandemic process. This exponentially growing epidemic process can only be managed by increasing the well-being of nurses and the risk of spreading the virus in the health sector can be kept to a minimum. Nurses play a crucial role in the coordination of health, care and support services and they are at the forefront in the fight against outbreaks. That's why they should be well supported by providing health safety by hospitals. In this case report, the experiences of a nurse giving the nursing care to COVID-19 positive patients are explained.

Keywords: Case report, clinical experience, pandemics
Sorumlu Yazar / Corresponding Author:

Canan Birimoğlu Okuyan

Sakarya Uygulamalı Bilimler Üniversitesi, Sağlık Bilimleri Fakülte-

si, Western Ontario Üniversitesi, Ontario/Kanada.

Tel: +902646160054

E-mail: cananbirimoglu@gmail.com; cbirimog@uwo.ca

\section{Yayın Bilgisi / Article Info:}

Gönderi Tarihi/ Received: 24/06/2020

Kabul Tarihi/ Accepted: 08/10/2020

Online Yayın Tarihi/ Published: 30/12/2020

Atıf/ Cited: Birimoğlu Okuyan C et al. COVID-19 Pozitif Hastaya Hemşirelik Bakımı Veren Bir Hemşirenin Deneyimleri: Olgu Sunumu. Online Türk Sağlık Bilimleri Dergisi 2020;5(4):705-708. doi: 10.26453/otjhs.757164

\section{GíRiş}

Salgın hastalıklar; çoğu insanı olumsuz etkileyen, sosyal ve ekonomik bozulmalara hatta ölümlere neden olan küresel bir sorundur. ${ }^{1}$ Aralık ayı 2019 da ilk olarak Çin'in Wuhan şehrinde ortaya çıkan ve insan sağlığını ciddi derecede tehdit eden Koronovirüs (COVID-19), 30 Ocak 2020'de tüm dünya için endişe verici küresel bir salgın olarak ilan edilmiştir. ${ }^{1}$ Salgın sürecinin sağlık bakım sistemi üzerinde, özellikle sağlık işgücü üzerinde olumsuz etkileri 
vardır. Sağlık hizmeti sağlayıcılarından önemli rolü olan hemşireler, COVID-19'a karşı savaşan, bu hastalığı kontrol etme ve hastaları rehabilite etmede önemli roller oynayan, hastanın hastaneye yatıştan taburcu olana kadar olan süreçte hastalarla sürekli temas halinde olan ve bu süreçte büyük bir kontamine olma riski ile karşı karşıya olan sağlık çalışanlarının en önemli grubudur. ${ }^{2}$ Salgın hastalıkların hemşireler üzerindeki risklerinin belirlenmesi hastaların uygun öz bakımı ve bakım kalitesi açısından önemlidir ve bir hemşirenin en önemli amacı hasta bakımıdır. ${ }^{3} \mathrm{Bu}$ doğrultuda, sunduğumuz olgu sunumu salgın sürecinde COVID-19 pozitif hastalara bakım veren bir hemşirenin karşılaştığg sorunlar ile ilgili duygu ve düşüncelerin açıklanması amacıyla yapılmıştır.

\section{OLGU SUNUMU}

Hemşirenin COVID-19 pozitif hastalara bakım verirken karşılaştığı sorunlar ile ilgili duygu ve düşüncelerinin yayınlanabileceğine ilişkin olarak hemşireye ayrıntılı bilgi verildi ve hemşireden yazılı, imzalı izin belgesi alınd1.

Kendi anlatımı ile COVID-19 pozitif hastaya bakım ve tedavi uygulayan bir hemşirenin karşılaştığı sorunlar: 28 yaşında; mesleğimin 6 . yılında, faklı birimlerde çalışmış ve aynı zamanda yoğun bakım deneyimi olan bir klinik hemşiresiyim. Dünya'nın her yerinde görülen bu salgın için büyük bir bilinmezlik içindeyiz ve hayatlarımız tamamıyla değişti diyebilirim. Çalıştığım hastanede bir klinik COVID19 tanısına sahip hastalar için ayrıldı ve bu insanlar için özel ekip oluşturuldu. Vaka sayılarının artması ile beraber çalışma saatleri de esnetildi. Hastaneye ziyaretçi kısıtlaması yapıldı. Gün geçtikçe vaka sayıları ile birlikte ölüm sayıları da beraberinde artıyordu. Salgınla mücadele etmek adına vaka sayısındaki artışa bağlı olarak birçok klinik hasta sayısını azaltmaya çalışarak tanıya sahip olmayan insanlar korunmaya çalışıldı. Yaklaşık 1 ay sonra ben de bu hastalığa spesifik olarak ayarlanmış yoğun bakımda çalışmaya başladım. Çalışmaya başladığım ilk gün ekip arkadaşlarımdan bir tanesi 'A rkadaşlar hepimiz birbirimize destek olacağız ve önce kendimizi korumamız lazım' dedi. Belki de hemşirelik mesleğine başladığımız ilk günden bu güne farkında olarak ilk defa bu kadar güçlü bir şekilde birbirimize kenetlendik, birbirimizi anlamaya çalıştık.

Bulaştan korunmak için genel olarak hazırlık için yoğun bakım dışında kirli ve temiz alanlar oluşturuldu. Koruyucu ekipman olarak gözlük, bone, maske, tulum ve eldiven kullanıyoruz. "Ekipman sikıntısı hiç olmadı ama psikolojik olarak hepimizi yıpratan bir süreçten geçiyoruz". Çünkü salgın hepimizi evlere kapattı ve biz sağlık çalışanları olarak salgınla mücadelenin en merkezi konumundayı.

Salgın sürecinde refahımız için işimiz zor ve stresimizi azaltmak için fiziksel destekten ziyade psikolojik desteğe ihtiyacımız var. Bunun için whatsapp üzerinden psikolojik destek grupları oluşturuldu. Bence bu yöntem bizler için etkili ve iyi değil. Kesinlikle "Yüz yüze veya kişiye özel spesifik olarak verilecek desteğin daha faydall olabileceğini düşünüyorum". Özellikle yoğun bakımda çalışacağımı öğrendiğim zaman hem kendimi hem de ailemi düşündüm. Şu soruyu kafamdan atamıyordum ' $Y a$ benim yüzümden onlara bir şey olursa?' İş yükümün üzerine bu endişe ve kaygı da eklenince kendimi daha da tükenmiş hissettim. Salgın sürecinde hastanenin, sağlık çalışanları için tahsis ettiği öğrenci yurdunda kalan birçok arkadaşım var. Eşimle aynı evde yaşıyor olmam onun risk altında olmasına neden olduğu için ben de nöbet çıkışlarında yurtta yaşamaya başladım, duşumu orda alıp, kirli formalarımı yıkayıp evime öyle geçiyordum. Ailem en büyük destekçim. Sürekli telefonla konuşarak bana destek oluyorlar ve güç veriyorlar. Fakat en çok kaygım "hastalığın bana bulaşmasından çok aileme bulaştırmak”. Bu nedenle “Hep bir arayış hep bir çözüm içindeyim... bulaşmayı nasıl önleyebilirim çünkü en ufak bir ihmal ya da dikkatsizlik riski artıracakt." bulaşıcılığı ancak mesafe ve koruyucu ekipmanlar ile sağlayabiliyorum.

Hastaların ihtiyaçlarını karşılayan fiziksel mesafe konusunda yoğun bakım temiz alandan bir cam ile ayrılıyor. Hastaları takip ettiğimiz monitörler mevcut böylelikle hastalar sürekli göz önünde tutuluyor. Ekip olarak 5 kişiyiz ve aynı anda hastalara bakım vermek için içeri girmiyoruz. Dönüşümlü olarak yoğun bakıma girip tedavimizi yapıyoruz. Yoğun bakımdaki hastalar genel olarak 65 yaş üstü bakım ihtiyacı olan hastalardan oluşuyor. Tedavi ve bakım sürecinde hasta ile fiziksel mesafeyi korumak ne yazık ki pek mümkün olmuyor. Koruyucu ekipmanı giydikten sonraki süreç en zorlu olanı. Tulumların içinde en az 2 saat duruyoruz ve çıktığımızda sırılsıklam oluyoruz. Bazen bir nöbette 3 forma değiştirmemiz gerekebiliyor. Gözlüklerimiz buharlaşıyor bu durum da bakım ve tedavi sürecimizi zorlaştırıyor. Koruyucu ekipman olarak kullandığım maskeden dolayı nefes alamıyor takmış olduğum gözlük genelde burnumda ve yüzümde bası oluşturmuş şekilde yoğun bakımdan çıkıyorum. Hastalarla kurduğumuz ilişkilerimiz de farklılaştı. Hemşirelik bakımı verirken hastalarla iletişim kurmam gerekirken; iletişim 
kurmakta zorlanıyor, işlem yaparken onları çok zor görüyorum. Çoğu zaman su bile içemiyor, fiziksel ihtiyaçlarımı karşılayamıyorum. Normal bir insan virüs riskine bir kez maruz kalırken biz birçok kez maruz kalıyoruz. Bu şekilde salgınla mücadele ederken COVID-19 (+) pozitif çıkan sağlık çalışanı arkadaşlarımızın haberini almak bizi daha da çok üzüyor. İnsanların evden çıkamadığı bir salgında biz en önde savaşıyor, bakım rolümüzü hakkıyla yapabilmek için fiziksel mesafeyi bazen ihmal etmek zorunda kalıyoruz. "Tek güvencemiz sadece ve sadece koruyucu ekipmanlar..." Hastalar yakınlarından uzakta yaşam mücadelesi veriyorken, sadece biz onların yanlarında olabiliyoruz. "Sevindiğimiz anlar da oluyor, mesela alkışlarla gönderdiğimiz iyileşmiş hastalar..." Onların yaşamlarına dokunmak hastalarımızın mutlu ve sağlıklı olması bizi çok mutlu ediyor. Üzüldüğüm nokta ise "gece gündüz bu süreçte çallşırken vaka sayıların azalmaslyla birlikte insanların alınan önlemlere uymamaları." Hemşireler bu sürecin ön cephesindeki sağlık çalışanları ama bu salgınla mücadele etmek, hastalara tulumlar ve diğer ekipmanlarla bakım vermek bunun karşılığında sadece alkışlanmak biz hemşireleri için yeterli değil. " $B u$ salgını önlemede rollerimiz çok büyükken hala özlük haklarımıza ilişkin sahip olduğumuz sorunlar var." Bu salgınla savaşırken evet korkuyoruz ve bu kadar ağır çalışma ile zor bir süreçten geçiyoruz ama işte kelimenin düğüm olduğu an..."her şeye rağmen mücadeleye devam ediyor, pes etmiyoruz, kendi canlmızdan çok karşımızdakinin canını düşünüyoruz". Yaşadığımız çok zor bir süreç; ne kadar devam edeceğini bilmediğimiz, bununla yaşamaya alışmak zorunda olduğumuz bir süreçte "sağlığınız için biz hep yanınızdayı".

\section{TARTIŞMA VE SONUÇ}

Pek çok bilinmeyen klinik yönü olan Koronovirüs (COVID-19), ortaya çıkan yeni bir hastalıktır. ${ }^{4} \mathrm{Hem}-$ şireler, dünyada üçüncü ölüm nedeni olarak kabul edilen bulaşıcı hastalıklardan biri olan COVID19'un olumsuz sonuçlarının hafifletilmesi ve sağlık hizmetlerinin yönetiminde çok önemli bir rol oynamaktadırlar. ${ }^{5}$ Ancak pandemi sürecinde topluma bakım verme konusunda profesyonel bir yükümlülüğe sahip olmasına rağmen hemşireler mesleklerini icra ederken COVID-19'a bağlı olarak vaka sayılarının sürekli artışı, zorlu çalışma koşulları, kişisel koruma ekipmanlarının yetersizliği, hastalığa özgü ilaçların eksikliği, yetersiz destek, yakınlarını korumak adına aileleri ile görüşememeleri ya da çalıştıkları kurumlardaki personel eksikliği nedeniyle evlerine gönde- rilememeleri, ${ }^{6}$ uzun çalışma saatleri ve çalışma ortamlarının güvensiz oluşu gibi yaşanılan durumlardan dolayı büyük sorunlarla mücadele etmektedirler. ${ }^{7} \mathrm{Bu}$ nedenlerden dolayı hemşireler işlerinden ayrılmaya bile karar verme durumunda kalmışlardır. ${ }^{8}$ $\mathrm{Bu}$ çalışmaya katılan hemşirenin endişeleri, COVID19 riski altında olduğu, virüsü bulaştırma korkusu yaşadığı ve bu süreçte stresli bir çalışma süreci geçirmesi ile bağlantılıydı. Sağlık çalışanları, pandemi sırasında virüs bulaşma konusunda genel halktan daha fazla endişeye sahiptir. ${ }^{9}$ Çin'deki COVID-19 salgını sırasında yapılan bir çalışmaya göre, sağlık çalışanları nüfusun çoğunluğuna kıyasla yüksek düzeyde kaygı yaşadıkları belirlenmiştir. ${ }^{10}$ Riski tamamen ortadan kaldırmak mümkün değildir ancak sağlık çalışanlarının özellikle hasta ile bakım rolünden dolayı içi içe çalışan hemşirelerin endişe ve kaygılarını dikkate almak, tele tıp hizmetleri, hasta danışma hatları, telefon triyaj sistemleri gibi yapılacak ihtiyatlı düzenlemeler ile virüs salgını daha sağlıklı ve güvenli bir şekilde garanti altına alınabilir. Bununla birlikte, pandemi ve salgın hastalıkların hemşireler üzerindeki deneyimlerini ve etkilerini anlamak, bu temel çalışanların işgücünde kalmaları için iyi bir şekilde desteklenmeleri ve toplumdaki yüksek sağlık gereksinimi sırasında kaliteli sağlık bakımın sağlanmasını kolaylaştırmak için hayati önem taşımaktadır. Sonuç olarak; COVID-19 hastaya bakım veren hemşire, COVID-19 riski altında olduğunu, özellikle virüsü ailesine bulaştırma korkusu yaşadığını ve salgın sürecinde stresli ve zor bir süreç geçirdikleri için fiziksel destekten ziyade psikolojik desteğe ihtiyaçları olduğunu ifade etmiştir. Bir pandemi veya salgın sırasında çalışmanın hemşireler üzerindeki fiziksel ve psikolojik etkisinin tanınması ve görünür hale getirilmesi gerekmektedir. Hemşireler ile yapılacak görüşmeler kaygılarını ve endişelerini azaltmaya yardımc olabilir ve vardiyalar sırasında mola verebilmeleri, hasta olduklarında izin alabilmeleri ve kaliteli bakım verebilmeleri için yeterli personel alınması şarttır. Aynı zamanda çalışanların yeterli dinlenmelerinin sağlanması, kritik kişisel ihtiyaçların giderilmesi, odak grup görüşmeleri ile bireysel psikolojik desteklerinin sağlanması, yiyecek, dinlenme molaları, boş zaman veya kendisine yeterli zaman ayırma imkanlarının ve koruyucu ekipmanların sağlanması kadar uzun vadede ekip performansının korunmasına da yardımcı olacaktır. Ek olarak ülkelerin kendi sosyal ve kültürel özelliklerine uygun korunmaya yönelik tedbirler konusunda bir uzman aracıl1ğıyla hemşirelere COVID-19 sürecinde ev rehberliği de sağlanabilir. 
Etik Komite Onayı: Çalışmamız olgu sunumu olduğu için etik kurul onayı gerekmemektedir. Hemşireden sözlü ve yazılı onam alınmıştır.

Çıkar Çatışması: Yazarlar çıkar çatışması bildirmemişlerdir.

Yazar Katkıları: Fikir - CBO; Veri toplanması ve işlemesi - CBO, EG, EY; Yazıyı yazan - CBO, EG, EY.

Hakem değerlendirmesi: D1ş bağımsız .

Teşekkür: COVID-19 sürecindeki hasta bakım ve deneyimi ile ilgili değerli duygu ve düşüncelerini paylaşan hemşiremize makaleye katkılarından dolayı çok teşekkür ederiz.

\section{KAYNAKLAR}

1. Fernandez PR, Lord H, Halcomb PE, ve ark. Implications for COVID-19: a systematic review of nurses' experiences of working in acute care hospital settings during a respiratory pandemic. Int J Nurs Stud. 2020;8:103637.

2. Eghbali M, Negarandeh R, Froutan R. COVID19 epidemic: Hospital-level response. Nurs Pract Today. 2020;7(2):81-3.

3. Ross A, Bevans M, Brooks AT, Gibbons S, Wallen GR. Nurses and health-promoting behaviors: knowledge may not translate into selfcare. AORN J. 2017;105(3):267-275.

4. Galehdar N, Kamran A, Toulabi, T. Heydari H. Exploring nurses' experiences of psychological distress during care of patients with COVID-19: a qualitative study. BMC Psychiatry. 2020;20:489.

5. WHO (2020) Clinical management of severe acute respiratory infection when COVID-19 is suspected, World Health Organisation, Interim guidance. Available from:https://www.who.int/ publications-detail/clinical-management-ofsevere-acute respiratory-infection-when novelcoronavirus-(ncov)-infection-is-suspected. Erişim tarihi 15 Haziran 2020.

6. Aumgaertner E, Karlamangla S. Doctors and nurses brace for coronavirus onslaught: 'What happens if I end up on a ventilator?' Available from: https://www.latimes.com/california/ story/2020-03-20/coronavirus-doctors-nursesfears-ventilator-icu-emergency. Erişim tarihi 18 Haziran 2020.

7. Hope K, Massey PD, Osbourn M, Durrheim DN, Kewley CD, Turner C. Senior clinical nurses effectively contribute to the pandemic influenza public health response. Aust J Adv Nurs.
2011;28(3):47.

8. Martin SD, Brown LM, Reid WM. Predictors of nurses' intentions to work during the 2009 influenza A (H1N1) pandemic. Am J Nurs. 2013;113(12):24-31.

9. Wu P, Fang Y,Guan Z,Fan B,Kong J,Yao Z,Hoven CW.The psychological impact of the SARS epidemic on hospital employees in China: Exposure, risk perception, and altruistic acceptance of risk. CJP. 2009;54:302-311.

10. Huang Y, Zhao N. Generalized anxiety disorder, depressive symptoms and sleep quality during COVID-19 outbreak in China: a webbased cross-sectional survey. Psychiatry Res. 2020;288:112954. 